\title{
Investigação matemática e educação financeira: manifestações de aprendizagem em um curso de \\ licenciatura
}

\author{
Math investigation and financial education: learning \\ manifestations in a graduation program
}

Investigación matemática y educación financiera: manifestaciones de aprendizaje en un curso de

licenciatura

PATRICIA FRANZONI (Da

MARLI TERESINHA QuARTIERI IDb

\section{Resumo}

Este artigo caracteriza-se como pesquisa qualitativa e tem como objetivo investigar a aprendizagem e principais dificuldades dos licenciandos em matemática de uma universidade no estado do Rio Grande do Sul, com relação a tarefas investigativas de educação financeira, a partir de questionário metacognitivo. A metacognição está relacionada à consciência do indivíduo sobre a sua própria aprendizagem. Os dados produzidos foram analisados mediante a análise textual discursiva, surgindo duas categorias: a) Manifestações de aprendizagem e; b) Análise das dificuldades durante a resolução da tarefa. Por meio deste estudo, conclui-se que a maioria dos alunos envolvidos na pesquisa aprenderam educação financeira a partir da resolução das tarefas investigativas, análise das dificuldades e discussões com a turma. As principais dificuldades encontradas estão relacionadas à falta de

\footnotetext{
a Universidade Federal do Rio Grande (FURG), Rio Grande, RS, Brasil. Doutora em Ensino e Mestra em Economia, e-mail: patriciafranzoni@furg.br

b Universidade do Vale do Taquari (UNIVATES), Lajeado, RS, Brasil. Doutora em Educação, e-mail: mquartieri@univates.br
} 
conhecimento de economia; insegurança na formulação de conjecturas e generalizações, em função da dependência da utilização de formulários; ausência de prática na resolução de problemas de caráter aberto. Os pequenos grupos quando compararam seus resultados, no momento da socialização para o grande grupo, perceberam que poderiam ter escolhido outros caminhos ou que algum fator importante, que poderia ter feito parte da análise, não tinha sido considerado, o que possibilitou diversas reflexões, fortalecendo o aprendizado e o desenvolvimento do espírito crítico e colaborativo.

Palavras-chave: Educação Financeira. Economia. Matemática. Metacognição.

\begin{abstract}
This article is characterized as qualitative research and aims to investigate the learning and difficulties of undergraduates in mathematics, from a university in the state of Rio Grande do Sul, regarding investigative tasks of financial education, based on a metacognitive questionnaire. The metacognition is related to the individual's consciousness about their own learning. The data produced were analyzed through discursive textual analysis, with two categories showing up: a) learning manifestations and b) analysis of the difficulties while performing the tasks. Through this study, we conclude that most of the students involved in the research have learned financial education from the investigative tasks, difficulty analyses and discussions with the class. The main difficulties found are related to the lack of knowledge in economics; insecurity when creating conjectures and generalizations, because of the dependence on the use of forms; the absence of practice in solving open problems. The small groups, when comparing their results, at the moment to socialize with the big group, realized they could have chosen a different path or that an important factor, which could have been part of the analysis, hadn't been considered, which enabled many reflections, strengthening the learning and the development of critical and collaborative thinking.
\end{abstract}

Keywords: Financial Education. Economics. Mathematics. Metacognition.

\title{
Resumen
}

Este artículo se caracteriza como una investigación cualitativa y tiene como objetivo investigar el aprendizaje y las dificultades de los alumnos de licenciatura en matemáticas, de una universidad de Rio Grande do Sul, en relación a tareas investigativas de educación financiera, a partir de cuestionario metacognitivo. La metacognición está relacionada a la consciencia del individuo sobre su propio aprendizaje. Los datos producidos fueran analizados mediante el análisis textual discursivo, surgiendo dos categorías: a) Manifestaciones de aprendizaje y; b) Análisis de las dificultades durante la solución de la tarea. Por medio de este estudio, se concluye que la mayoría de los alumnos involucrados en la investigación han aprendido educación financiera a partir de la solución de tareas investigativas, análisis de 
dificultades y discusiones con la clase. Las principales dificultades encontradas están relacionadas a la falta de conocimiento de economía; inseguridad en la creación de conjeturas y generalizaciones, a causa de la dependencia del uso de formularios y; ausencia de práctica en la solución de problemas abiertos. Los pequeños grupos cuando compararon sus resultados, en el momento de socialización para el gran grupo, percibieron que habrían podido elegir otros caminos o que algún factor importante, que habría podido hacer parte del análisis, no habría sido considerado, lo que posibilitó diversas reflexiones, fortaleciendo el aprendizaje y el desarrollo del espíritu crítico y colaborativo.

Palabras clave: Educación Financiera. Economía. Matemática. Metacognición.

\section{Contextualizando o estudo}

Segundo Franzoni, Del Pino e Oliveira (2018), na maioria das escolas, o professor ministra aulas no quadro negro com frequência, o que desestimula a criatividade, o pensamento crítico e o envolvimento dos alunos, que acabam memorizando conceitos somente para serem aprovados na disciplina. Para a maior parte dos alunos, a construção do conhecimento em sala de aula está alheia a suas experiências cotidianas, não existindo conexão entre o que se aprende na escola e o mundo ao seu redor. De acordo com Santos (2007), as crescentes transformações sociais impõem às instituições de ensino um repensar sobre o processo de ensinagem, visando a formação de um cidadão com um novo perfil, em que habilidades como proatividade, cooperação, criticidade, dentre outras, se sobressaem em detrimento da simples memorização e repetição. Isso faz inferir que essa atual configuração tem como prioridade o desenvolvimento do pensamento do aluno como uma dimensão fundamental da cognição.

Assim, percebe-se que a matemática aprendida pode estar limitada à repetição de registros referendados por quem a ensina. Nesse caso, acaba-se prejudicando a criatividade na aprendizagem. De acordo com Gontijo (2006) a criatividade em matemática compreende a capacidade de encontrar maneiras e caminhos para resolver problemas, inventar fórmulas e encontrar métodos originais para resolver os problemas não tradicionais. Ou seja, desenvolver a capacidade do aluno de envolver-se com a própria aprendizagem, criar estratégias próprias, lhe oportunizar envolver-se com tarefas que demandem exploração e investigação. Nesse sentido, os 
professores precisam atuar como mediadores, promovendo debates, proporcionando momentos de discussão e reflexão em sala de aula, valorizando o conhecimento dos alunos a partir de metodologias diferenciadas de ensino, como por exemplo, a investigação matemática, tornando dessa forma o ensino mais atrativo.

Ponte, Brocardo e Oliveira (2015, p. 23) definem a investigação matemática como uma "atividade de ensino-aprendizagem" que envolve quatro principais momentos. O primeiro momento refere-se ao conhecimento inicial, envolvendo a verificação, análise e a elaboração de questões em referência à situação-problema. O segundo momento envolve a elaboração de ideias e constatações, que se baseia em suposições elaboradas a partir de uma situação — essas hipóteses são chamadas de conjecturas. O terceiro momento implica a realização de testes das conjecturas, na qual será definido se a hipótese fundamenta-se ou não como verdadeira. Ao final, na quarta etapa, ocorre a demonstração e avaliação da situação, sendo que essa sempre deve vir acompanhada de uma argumentação que justifica o seu raciocínio.

Nesse contexto, a investigação matemática está relacionada, segundo Ponte, Brocardo e Oliveira (2015), à formulação de conjecturas que se procura testar e provar, bem como a apresentação dos resultados e discussão e argumentação com os seus colegas e professor. Goldenberg (1999, p. 37) complementa que as tarefas investigativas "motivam os alunos, e ainda, desenvolvem capacidades que contribuem para um conhecimento mais amplo de conceitos e facilitam a aprendizagem". Logo, esta metodologia oportuniza aos alunos uma ambiência exploratório-investigativa, possibilitando a criação de estratégias de enfrentamento de problemas que têm por objetivo aprendizagens de assuntos do âmbito escolar.

Portanto, percebe-se que é importante o professor utilizar a investigação, deixar o aluno apresentar suas próprias respostas e discutir os resultados obtidos, fomentando o desenvolvimento da criatividade e criticidade. Cabe ao professor colocar seus alunos em situações em que se mobilizem com tarefas investigativas, como por exemplo vinculadas à educação financeira, pois segundo a Base Nacional Comum Curricular - BNCC (BRASIL, 2017) um dos aspectos a ser considerado na disciplina de matemática é o estudo de conceitos básicos de economia e finanças, visando justamente à educação financeira dos alunos. 
Assim, "podem ser discutidos assuntos como taxas de juros, inflação, aplicações financeiras (rentabilidade e liquidez de um investimento) e impostos" (BRASIL, 2017, p. 269). Ainda, segundo Brasil (2017) entre as habilidades dos alunos estão: resolver e elaborar problemas do cotidiano, da matemática financeira e de outras áreas de conhecimento; elaborar planilhas para o controle de orçamento familiar; resolver e elaborar problemas envolvendo taxa de câmbio, porcentagens em diversos contextos e juros compostos, destacando o seu crescimento exponencial. $\mathrm{O}$ cidadão deste século na área da matemática precisa "utilizar estratégias, conceitos e procedimentos matemáticos para interpretar situações em diversos contextos, sejam atividades cotidianas, sejam fatos das ciências da natureza e humanas, ou ainda questões econômicas” (BRASIL, 2017, p. 523).

Dessa forma, é possível que os alunos sejam capazes de fazer melhores escolhas, ter consciência sobre seus atos e consequências, refletir, analisar, discutir e interpretar situações diversas, se posicionando criticamente frente a algum tema e/ou problema financeiro. Contudo, segundo Teixeira (2015), existe uma preocupação excessiva em ensinar matemática financeira por meio de fórmulas e tabelas, sem fazer referência ao cotidiano, o que dificulta o aprendizado, acarretando desinteresse do estudante. Ainda de acordo com o autor é preciso unir teoria e prática, objetivando conectar essa disciplina com a educação financeira.

Kistemann Jr. (2011) enfatiza a necessidade de incluir educação financeira em diversos contextos de formação dos estudantes desde a educação elementar até o ensino superior, objetivando fornecer aos indivíduos-consumidores noções básicas sobre economia e consumo. Além disso, existe a necessidade de proporcionar-lhes estratégias que auxiliem na tomada de decisões e condução de situações cotidianas, e se posicionarem como indivíduos críticos. Assim sendo, de acordo com Franzoni, Martins e Quartieri (2018) a falta de entendimento sobre economia pode ser um dos empecilhos para a promoção do aumento do nível de bem-estar, pois uma sociedade informada e com conhecimento é capaz de realizar melhor suas escolhas. Portanto, a ideia de escolher a investigação matemática para ensinar educação financeira é contribuir na aprendizagem e no desenvolvimento do pensamento crítico do aluno no processo de tomada de decisão. 
Diante deste cenário, o objetivo do presente estudo ${ }^{1}$, de abordagem qualitativa, foi investigar a aprendizagem e principais dificuldades dos licenciandos em matemática, de uma universidade no estado do Rio Grande do Sul, com relação a tarefas investigativas de educação financeira, a partir de questionário metacognitivo. A palavra metacognição foi referenciada, pela primeira vez, pelo psicólogo americano John Hurley Flavell, em 1971, como a tomada de consciência do aluno sobre os seus conhecimentos (ROSA, 2011). Para Grillo e Freitas (2010, p. 46) “a metacognição consiste em uma atitude reflexiva pela qual o aluno toma consciência dos próprios processos mentais". Portanto, a metacognição é a forma como o sujeito aprende e o aluno, quando passa a refletir sobre o modo como aprende, tem condições de adotar estratégias para ter uma aprendizagem mais significativa.

Salienta-se que os dados foram analisados a partir da Análise Textual Discursiva (MORAES; GALIAZZI, 2016) e a aplicação do questionário metacognitivo possibilitou às pesquisadoras verificar se cada situação-problema proposta foi assimilada pelos alunos. Esse instrumento pode proporcionar aos licenciandos a revisão do raciocínio, o monitoramento do pensamento, a observação das dificuldades e potencialidades encontradas e a avaliação do próprio aprendizado.

Ademais, este estudo tem a importância de contribuir para a formação inicial do futuro professor de matemática. Para tanto, além desta introdução, a segunda seção apresenta a metodologia realizada para efetivar esta pesquisa. A terceira seção faz referência à análise dos dados, apresentando os principais resultados. Por fim, a última seção explicita as conclusões deste estudo.

\section{Metodologia}

Para alcançar o objetivo proposto, ou seja, investigar a aprendizagem e principais dificuldades com relação ao tema de educação financeira, a pesquisa foi realizada com oito estudantes de uma universidade no estado do Rio Grande do Sul, na disciplina de matemática financeira, posicionada no $6^{\circ}$ semestre da matriz curricular do curso de licenciatura em matemática. A turma com oito estudantes foi

\footnotetext{
1 O presente trabalho foi realizado com apoio da Coordenação de Aperfeiçoamento de Pessoal de Nível Superior - Brasil (CAPES) - Código de Financiamento 001.
} 
escolhida, entre as diversas de matemática financeira na universidade, por se tratar de futuros professores de matemática da educação básica e/ou ensino superior que, provavelmente, terão que ensinar conteúdos de educação financeira. Ademais, cabe destacar que os alunos concordaram em participar da pesquisa e assinaram o termo de consentimento livre e esclarecido, sendo que o tamanho da amostra é igual ao número total de alunos matriculados na disciplina, o que foi suficiente para as conclusões desse estudo.

Com relação às tarefas investigativas, os alunos tiveram a oportunidade de vivenciar, na prática, os quatro momentos de realização da investigação matemática, conforme citado anteriormente por Ponte, Brocardo e Oliveira (2015), no qual foram exploradas dez atividades: cafeteria e a tomada de decisão, custo de passagem de avião e decisão de compra, custo de viagem internacional e decisão de compra, porcentagem, regimes de capitalização simples e composto, formas de pagamento e juros compostos, formas de investimento, previdência complementar, aluguel ou financiamento imobiliário, e produção de tarefa investigativa sobre educação financeira.

O objetivo principal de cada tarefa investigativa de educação financeira foi analisar o comportamento do consumidor/pensamento do aluno no processo de tomada de decisão em situações-problema que fazem parte do cotidiano. Explicitar, também, as implicações dos juros compostos ao longo do tempo; a diferença entre valor à vista e a prazo; a importância de fazer pesquisa de mercado e comparar preços, de forma a minimizar custo e/ou maximizar satisfação; o quanto o entendimento de porcentagem, taxas de câmbio, conversão de moeda, taxas pré e pós-fixada de juros podem facilitar o processo de escolha; que formas de investimento, planos de previdência, regimes de capitalização, formas de financiamento (imobiliário, leasing, consórcio, crédito direto ao consumidor) são mais vantajosos, de acordo com o cenário da economia atual e suas possíveis previsões. Enfim, como o entendimento de economia e matemática financeira influenciam na tomada de decisão do consumidor e são importantes para se atingir a educação financeira.

As situações-problema elaboradas tiveram o intuito de atender, também, ao objetivo e habilidades previstas da disciplina de matemática financeira, contribuindo na formação inicial dos licenciandos, ao estabelecer relações entre a matemática 
financeira com a educação financeira a partir de tarefas investigativas. Dessa forma, acredita-se que os futuros professores poderão se sentir mais preparados para ensinar educação financeira.

Em função do tamanho da turma, foram formadas quatro duplas para trabalharem em conjunto. Os pequenos grupos foram montados a partir da escolha de uma palavra por cada aluno: Investigação, Matemática, Finanças e Ensino. Cabe destacar que todas as tarefas investigativas foram pensadas para o ensino médio, mas podem ser adaptadas para o ensino fundamental. Após o desenvolvimento de cada tarefa investigativa nos pequenos grupos, os alunos socializaram as respostas para a turma (grande grupo).

$\mathrm{Na}$ sequência, cada aluno se dirigia ao Laboratório de Informática para responder ao questionário metacognitivo (que foi realizado também após cada tarefa investigativa), com a finalidade de analisar as percepções dos alunos com relação às tarefas investigativas e a sua própria aprendizagem, conforme Quadro 1 a seguir:

Quadro 1 - Questionário - Tarefa Investigativa e Aprendizagem

\section{NOME:}

1) Descreva, de forma sucinta, a importância e objetivo da questão-problema apresentada.

2) Quais estratégias foram utilizadas no desenvolvimento da atividade de investigação matemática? Que hipóteses foram estabelecidas para formalizar o raciocínio? As conjecturas foram testadas e validadas?

3) É preciso ter conhecimento de algum conceito de economia na questão-problema? Justifique:

4) Que dificuldades foram encontradas na resolução e quais seriam as causas?

5) Você considera que existiu colaboração, interação e motivação de todos os membros no desenvolvimento da atividade de investigação matemática? Justifique a sua resposta.

6) O que você aprendeu com essa atividade? De que forma existiu aprendizado com a atividade investigativa?

7) Ressalte pontos positivos e negativos da atividade.

8) Se você tivesse que avaliar o seu conhecimento sobre o tema da questão, em uma escala de zero a dez, como seria? Justifique a sua resposta para cada nota.

Ex-ant atividade:

Ex-post atividade:

Observação: Ex-ant atividade = conhecimento sobre o tema da questão anterior a resolução pelo grupo, demais grupos (socialização) e discussão. Ex-post atividade = conhecimento sobre o tema da questão posterior a resolução pelo grupo, demais grupos (socialização) e discussão.

9) Você considera que a atividade elaborada de investigação matemática pode ser utilizada para ensinar educação financeira na Escola Básica? Justifique a sua resposta.

Fonte: Elaborado pelas autoras. 
Segundo Rosa (2011), o objetivo do questionário metacognitivo é verificar se os alunos tiveram dificuldades nas atividades, qual foi o entendimento e que estratégias foram utilizadas na resolução da questão, se houve aprendizado, como aprenderam, além de comprovar, a partir dos resultados, se o problema de pesquisa do estudo foi respondido. Metacognição, segundo Flavell (1979) está associada ao conhecimento que o indivíduo tem sobre a sua cognição quando reflete como pensa, memoriza e aprende uma determinada tarefa; é a tomada de consciência do seu próprio saber. Assim sendo, o questionário foi elaborado com o propósito de investigar a aprendizagem de cada aluno, por isso foi respondido individualmente, logo após a socialização para a turma do que foi desenvolvido nos pequenos grupos. Por questões éticas, não são divulgados os nomes dos participantes da pesquisa, identificados de A1 a A8.

Diante disso e com base no objetivo proposto, este estudo se caracteriza como uma pesquisa qualitativa. Esta, segundo Gerhardt e Silveira (2009, p. 31-32), "não se preocupa com representatividade numérica, mas com a compreensão de um grupo social, com aspectos da realidade que não podem ser quantificados, centrando-se na compreensão e explicação da dinâmica das relações sociais".

Os dados emergentes foram analisados mediante a aplicação da ATD (Análise Textual Discursiva) que, conforme Moraes e Galiazzi (2016), configura-se como uma metodologia de etapas extremamente minuciosa, requerendo do pesquisador a atenção e a rigorosidade em cada etapa do processo. A ATD visa, inicialmente, à desmontagem dos textos e seu exame nos mínimos detalhes. Na sequência, desenvolve-se o estabelecimento de relações entre cada unidade, procurando-se a identidade entre elas para, em seguida, captar o que emerge da totalidade do texto em direção a uma nova compreensão desse todo.

A ATD, de acordo com Moraes e Galiazzi (2016) é composta por três etapas, sendo a primeira delas o processo de unitarização, em que é desconstruído o texto, fragmentando-o em unidades de significado. O processo de unitarização é, portanto, a etapa essencial no desenvolvimento da ATD, pois, nesta unidade, estão contidas as mensagens mais significativas dos textos analisados. A segunda se constitui na 
organização de categorias, a qual pode ser constantemente reagrupada. Por fim, na terceira, produz-se um metatexto com as novas compreensões obtidas.

Dessa forma, na primeira etapa os dados individuais do questionário metacognitivo foram organizados, separadamente, em um quadro e cada coluna correspondia a uma pergunta subjetiva na qual foram colocadas as palavras-chave a ela referentes. Na segunda etapa foram estabelecidas as categorias para, na última etapa da ATD, produzir os metatextos por categoria, ligando o aporte teórico deste estudo às respostas dos alunos.

\section{Análise e Resultados}

$\mathrm{Na}$ primeira fase deste estudo, os oito licenciandos em Matemática tiveram que responder um questionário sobre educação financeira, com o objetivo de investigar os conhecimentos prévios a respeito do tema. Os dados da primeira etapa da pesquisa demonstraram que existe dificuldade por parte de quatro alunos em definir educação financeira e compreender a diferença entre esta e a matemática financeira, tendo um aluno inclusive deixado a questão em branco, sob a justificativa de não saber responder. Foi constatado, também, que a maioria dos licenciandos não conseguiu estabelecer relações da educação financeira com os temas economia e sustentabilidade, sendo que apenas um aluno obteve êxito na conexão.

No entanto, com a análise dos dados do questionário metacognitivo (Quadro 1), a partir da Análise Textual Discursiva (ATD), foi possível atingir o objetivo proposto, ficando evidente a ampliação do conhecimento de educação financeira dos licenciandos por meio da metodologia da investigação matemática, reflexões durante a resolução das tarefas investigativas nos pequenos grupos e debates no momento de socialização das atividades para o grande grupo.

Cabe destacar que os dados analisados neste artigo foram retirados apenas da aplicação individual do questionário metacognitivo de cada tarefa investigativa, mas foram utilizados outros instrumentos de coleta de dados na pesquisa (gravações nos pequenos grupos, filmagens no momento da socialização das atividades para o grande grupo e discussões extra-classe no fórum do ambiente virtual - Plataforma Moodle) para comprovar os resultados deste estudo. As mesmas tarefas investigativas foram 
aplicadas posteriormente em outra turma, com doze alunos, do curso de licenciatura em matemática, resultando nas mesmas categorias.

Inicialmente surgiram quatro categorias, a saber: a) Contribuições da investigação matemática no processo de ensinagem de educação financeira, a partir de trabalhos em pequenos grupos, formulação de conjecturas, estratégias de resolução, desenvolvimento da criatividade, autonomia e argumentação durante a exploração das questões abertas e possibilidades de desfecho; b) Importância do conhecimento de matemática, matemática financeira e economia no processo de ensinagem de educação financeira; c) Desenvolvimento do pensamento crítico em situações-problema do cotidiano (ligação teoria e prática); d) Educação financeira, sustentabilidade e tomada de decisão. Essas quatro categorias foram reagrupadas nas seguintes: 1) Manifestações de aprendizagem e 2) Análise das dificuldades durante a resolução da tarefa. A seguir, apresentam-se as categorias emergentes com declarações dos alunos, bem como a referida discussão e imbricação com alguns autores.

\section{a) Manifestações de aprendizagem}

Os alunos A1, A2 e A4 destacam que o conhecimento de educação financeira está vinculado a outros saberes, ao considerarem que a educação financeira envolve tanto o conhecimento de matemática financeira como de economia para solucionar problemas financeiros do cotidiano:

A educação financeira compreende ter noção tanto de Matemática Financeira, como de Economia para enfrentar problemas do nosso cotidiano (A1).

Educação financeira, não é somente saber das fórmulas da Matemática Financeira, envolve o conhecimento de planejamento financeiro, consumo e poupança, para as pessoas não se endividarem e viverem melhor (A2).

Educação financeira abrange mais a questão da consciência consumista, sustentabilidade, prevenções econômicas, análise dos custos e benefícios individuais e sociais para não cair em ciladas em situações do cotidiano (A4).

A escassez, de acordo com Mankiw (2005), implica que os consumidores devem fazer escolhas, agindo racionalmente, ou seja, os consumidores devem ponderar os custos e benefícios de cada possibilidade sempre que se deparam com 
um processo de tomada de decisão, como realça a aluna A4, quando estabelece relações da educação financeira com os temas economia e sustentabilidade.

A resposta do aluno A2 sobre o tema de educação financeira vem ao encontro de Teixeira (2015) quando destaca que é preciso unir teoria e prática, objetivando conectar a disciplina de Matemática Financeira com o conteúdo de educação financeira. Ainda, segundo o autor, a Matemática Financeira trata do conhecimento de fórmulas, estuda o valor do dinheiro no tempo, enquanto a educação financeira está relacionada ao gerenciamento da renda, às decisões de consumo e de investimento, de forma a aumentar a qualidade de vida, como ressalta o estudante A2.

O aluno A1 evidencia que a produção, troca de atividades e saberes, a cooperação e a liberdade proporcionadas pela metodologia da investigação matemática, além de serem prazerosas, são fundamentais para a aprendizagem:

Gosto de criar problemas, achei sensacional essa atividade, aprende-se muito, no início sempre é um pouco trabalhoso e desafiador, mas ao mesmo tempo é prazeroso, porque dá liberdade para os alunos serem os construtores de seu próprio saber. O aluno precisa ser criativo, usar da intuição e detectar possíveis erros para que o outro grupo consiga resolver a atividade com êxito. A troca de questões e saberes, cooperação e liberdade que a investigação matemática proporcionou foi algo muito positivo (A1).

O aluno A2 salienta que aprendeu com a produção, resolução, discussão e reflexão das tarefas investigativas:

Criar um problema faz parte de ser professor, temos que estar sempre preparados. Aprendi por duas vezes, criando uma atividade de investigação e resolvendo-a para que não tivesse erro quando o outro grupo fosse solucionar, aprendi também quando tivemos que explicar para a turma a atividade do outro grupo, como pensamos, o que descobrimos, chegamos ao mesmo resultado do grupo que trocou a atividade conosco, mas por meios diferentes. $O$ legal dessa atividade é que tivemos o prazer de nos sentir professor (A2).

De acordo com as respostas de A1 e A2, percebe-se que o conhecimento metacognitivo está atrelado à reflexão do aluno sobre seus conhecimentos e ao sentimento deste em relação à atividade e como as suas experiências podem contribuir na escolha da estratégia para resolver o problema. Rosa (2011, p. 31) complementa:

O aluno deve ser capaz de, de posse desses novos saberes, resolver novas situações-problema, realizar atividades de forma a obter êxito em seus propósitos e 
ser capaz de gerenciar seu processo de apropriação dos saberes. Isso se refletirá na sua autonomia cognitiva, pela qual se busca que os estudantes adquiram conhecimentos suficientes para saber como aprender e, assim, construir seu modo de aprender de forma a utilizá-lo por toda a vida.

A aluna A7 ao concluir os quatro passos da investigação matemática destaca que compreendeu a atividade, que existiu aprendizado ao obter êxito na validação das conjecturas e tem certeza da sua aplicação em outras situações da mesma natureza:

Encontrando, testando e validando as generalizações, estamos aprendendo e entendendo o que acontece e podemos aplicar tais fórmulas em outros acontecimentos de mesma natureza (A7).

Nesse contexto, segundo Abrantes (1999, p. 155), "uma contribuição da prática de atividades que envolvem os alunos em problemas abertos é o fato de lidar com processos fundamentais da atividade e do pensamento matemático, como formular problemas e fazer e demonstrar conjecturas”. Assim, a metacognição, de acordo com Peixoto, Brandão e Santos (2007), desenvolve-se a partir da capacidade do aluno de refletir sobre seu processo de conhecimento durante a realização dessas tarefas, sobre os processos mentais que facilitam essa realização e sobre as estratégias que utiliza para a resolução de problemas.

O aluno A6 ressalta que foi possível avaliar o raciocínio e compreender a atividade de modo geral no momento em que as descobertas foram socializadas e discutidas pela turma:

Iniciamos a tarefa usando regra de três nos nossos cálculos e a partir disso começamos a formalizar nosso pensamento, socializando com os colegas foi possível avaliar nosso raciocínio e compreender que fatores deixamos de considerar durante a resolução. O aluno a partir de cálculos simples pode chegar em fórmulas mais elaboradas (A6).

Portanto, pode-se inferir, a partir das respostas de A1, A2, A6 e A7, que existiu aprendizado com o desenvolvimento da tarefa investigativa. "A metacognição é a consciência de si próprio, conhecendo seu processo de aprender [...]. É um processo de interação, em que os elementos principais são seus processos de aprendizagem" (BEBER; SILVA; BONFIGLIO, 2014, p. 145). A aluna A5 frisa a importância da 
produção de uma situação-problema investigativa no último dia de aula como fechamento do aprendizado:

Foi muito importante essa atividade como fechamento de nosso aprendizado, pois nos mostrou o quanto tivemos a capacidade de formular uma questão e o quanto nós aprendemos ao longo do bimestre (A5).

Dessa forma, a matemática desenvolveu a capacidade dos futuros professores de comunicarem-se matematicamente. A partir da elaboração de tarefa investigativa, descrições, representações, apresentações de resultados e argumentações sobre as conjecturas encontradas foi possível fortalecer o aprendizado. A metacognição, segundo Flavell (1979) está relacionada ao conhecimento que o aluno tem sobre a sua aprendizagem, o que vem ao encontro do pensamento de A5, A6 e A7.

O aluno A1 destaca ser necessário analisar outros fatores que podem influenciar no processo de tomada de decisão, que as escolhas não são tão simples como parecem e que podemos perder dinheiro, avalia a atividade como útil para outras situações e que auxiliou na aprendizagem. Em efeito:

O que percebo nessa atividade é que não prestamos muita atenção sobre vários fatores que influenciam na hora de fazer uma escolha de modo a economizar nosso dinheiro. Nessa atividade, foi notório que precisamos levar em conta vários outros motivos antes de podermos decidir, olhando para o problema era bem simples e objetivo. Entretanto, após analisar outras situações foi notório que fazemos coisas sem pensar e, isso, faz desperdiçar dinheiro sem necessidade, enfim a atividade foi útil e de grande aprendizagem (A1).

Partindo desse pressuposto, não existe uma única resposta, em função da diversidade de fatores que podem influenciar nos processos decisórios, é importante que o professor instigue a investigação, possibilite ao aluno argumentar, apresentar as suas próprias ideias e participar das discussões, evitando prejudicar o desenvolvimento da criatividade, criticidade e a própria aprendizagem. Ponte, Brocardo e Oliveira (2015) destacam que ao resolvermos um problema, temos um caminho de descobertas e esse processo pode se tornar mais significativo que a sua solução. Ainda segundo os autores (2015, p. 23) o “[...] envolvimento ativo do aluno é a condição fundamental da aprendizagem". Sendo assim, é preciso desenvolver a 
capacidade do aluno de envolver-se com a própria aprendizagem, criar estratégias próprias, lhe oportunizar envolver-se com atividades que demandem exploração.

As alunas A4, A5 e A7 constatam que a investigação matemática é uma forma de aprendizado diferenciada, em que o aluno precisa refletir e buscar seu próprio conhecimento. A interação e a colaboração que a investigação matemática proporciona auxiliam na compreensão das tarefas e são importantes para o aprendizado:

A atividade investigativa gerou um aprendizado diferenciado, pois aprendemos entre nós mesmos e vencemos as dificuldades através de um diálogo em conjunto. O nosso grupo é bastante colaborativo, interativo e participativo, facilitando a realização dos cálculos e a compreensão das questões (A4).

A forma de aprendizado diferenciada, propondo primeiramente uma situação-problema e fazendo com que o grupo pense e questione pode ser um ponto positivo, pois instiga os alunos a buscarem o próprio conhecimento. Nosso grupo sempre interage e colabora uns com os outros. E essa colaboração aumenta a capacidade de aprendizado no grupo e da turma inteira, pois nos instiga a pensar em várias possibilidades em conjunto e discutir uns com os outros, a atividade é simples, mas ao mesmo tempo interessante e divertida (A5).

A cooperação que as atividades de investigação proporcionaram e a professora nos instigando favoreceu o aprendizado do conteúdo e estimulou a turma a participar das discussões, proporcionando uma maior reflexão e compreensão sobre cada situação, estou muito satisfeita com as aulas, o ensino deveria ser dessa forma (A7).

Portanto, os trabalhos em pequenos grupos, segundo Masetto (2003, p. 119) “agregam em si a possibilidade de desenvolver vários aspectos de aprendizagem: aprofundamento de conhecimento, compreensão do assunto, habilidade de trabalhar em grupo, ouvir, dialogar e aprender com colegas". As atividades em pequenos grupos permitem que os alunos dialoguem sobre os problemas vivenciados, construindo espaços de ressignificação da sua realidade e aprendizagem.

Nesta perspectiva, de acordo com Peixoto, Brandão e Santos (2007), a metacognição é a consciência do modo pelo qual o conhecimento é construído, como destacam as alunas A4, A5 e A7, tornando-se possível que os próprios indivíduos gerenciem este processo, utilizando estratégias metacognitivas para a aprendizagem e resolução de problemas em situações cotidianas. Assim sendo, segundo Beber, Silva e Bonfiglio (2014) a metacognição é a consciência que o aluno tem de si próprio e os aspectos de cognição estimulam a confiança, a autoestima e o afeto. Os alunos A1 e 
A3 destacam que conseguiram compreender o que vem a ser taxa de câmbio a partir da atividade de investigação matemática:

A atividade foi ótima, visto que eu que não sabia o que era taxa de câmbio consegui formalizar e definir tal conceito que nunca tinha visto antes. Isso mostra que fazer a construção do conhecimento com os estudantes é a melhor forma de ensinar. Gosto quando aprendo coisas que não tinha conhecimento (A1).

Aprendi muito com esta atividade, pois eu nem imaginava o que era câmbio quando falavam na televisão, parecia coisa de outro mundo, algo que era fora do meu entendimento. Agora entendi sobre desvalorização da moeda e ter um pensamento lógico (A3).

Desse modo, a investigação matemática contribui para a integração e socialização, pois ela oportuniza um ambiente estimulador e criativo, onde o aluno tem a liberdade de expor seus pensamentos e resoluções aos colegas e ao professor. Em vista disso, "o professor precisa estar em constante formação, buscando sempre contribuições e estratégias metodológicas que visem aprendizagem e a formação de cidadãos ativos e críticos, pois afinal formar cidadãos é uma das funções do professor" (MOREIRA et al., 2017, p. 8).

Conforme o relato dos alunos A4, A5 e A6 a seguir, pode-se constatar que as tarefas de investigação matemática contribuíram no desenvolvimento do espírito crítico, pois foi necessário analisar os custos e benefícios de todas as possibilidades possíveis para um processo de tomada de decisão:

Estou aprendendo muito com essas atividades, a ser mais econômica e crítica, pois precisamos criar suposições e analisar várias possibilidades, durante o processo de tomada de decisão, para minimizar os custos ao máximo (A4).

É importante que haja a realização desse tipo de atividade que nos instiga, faz a gente aprender, nos ajuda a pensar e desenvolver o pensamento crítico. Precisamos de um pensamento crítico dos custos e benefícios que iremos ter a cada situação para fazer a melhor escolha (A5).

Aprendemos a ser mais críticos em relação à análise de preços de passagens de avião e levar em consideração os possíveis imprevistos que possam ocorrer. Ainda, se fizermos uma viagem internacional poderemos calcular o dinheiro necessário para a viagem e qual a opção mais vantajosa e econômica (A6). 
O pensamento crítico é imprescindível no processo de tomada de decisão, levando em consideração a relação custo-benefício ${ }^{2}$, como ressalta a aluna A5, para que se possa fazer a melhor escolha. Na época dos PCNs (Parâmetros Curriculares Nacionais), de acordo com Brasil (1998), já se sinalizava que os alunos, na disciplina de matemática, deveriam ser capazes de questionar a realidade, formular problemas e resolvê-los, utilizando do pensamento lógico, da criatividade, da intuição e da capacidade de análise crítica.

Moreira et al. (2017, p. 8) complementam: "na disciplina de matemática é necessário levar em consideração problemas que envolvem o cotidiano dos alunos, que os levem a refletir, investigar, buscar soluções e participarem criticamente no processo do ensino e aprendizagem [...]". Nessa perspectiva e conforme os relatos dos alunos A1, A2 e A5, a seguir, as tarefas de investigação matemática tornam-se mais interessantes à medida que é possível estabelecer relações com situações-problema do cotidiano:

Como professor de matemática, é necessário elaborar atividades e fazer associação com nosso cotidiano expondo os conteúdos para que aja aprendizado. Essa atividade explorou muito bem nossa criatividade para fazer conexões do conteúdo com o cotidiano (A1).

Eu me viro nessas situações quando enfrento-as, porém ao fazer uma atividade como essa estou aprimorando meu raciocínio para em uma situação real eu estar preparado [...] (A2).

A atividade investigativa pode ser um método válido para se ensinar educação financeira, ainda mais quando está relacionada a nossa vida, a nossa realidade, isso gera interesse no estudante através de um desafio em grupo, fazendo com que ocorra motivação para a resolução do problema (A5).

Skovsmose (2000) destaca que a educação matemática não se reduz à técnica de ensinar matemática, mas se configura como uma ação de educar matematicamente para a vida. É possível construir conhecimento quando o estudante estabelece relações entre teoria e prática, percebe a ligação do conteúdo e a sua aplicação no

\footnotetext{
2 É preciso analisar o custo-benefício, ou seja, "comparar os custos com os benefícios que provavelmente resultarão do investimento. Deve-se escolher, entre as várias opções, aquela que apresenta a maior diferença positiva entre os benefícios e os custos" (SANDRONI, 2008, p. 216).
} 
cotidiano, como destacam os alunos A2, A5, A7 e A8, o que vem ao encontro do pensamento de Skovsmose (2000), Moreira et al. (2017) e D’ Ambrosio (2000):

O legal é que os números não são os únicos que devemos levar em consideração na resposta final, devemos repensar as possibilidades de investimento a partir de diversos outros fatores, como prazo, imposto de renda, inflação, necessidade de tirar o dinheiro antes, falência do banco, entre outros. Nós como matemáticos só pensamos nos números. Esse tipo de problema faz a gente abrir a mente. Educação financeira, não é somente saber das fórmulas da matemática financeira, envolve o conhecimento de planejamento financeiro, consumo e poupança, para as pessoas não se endividarem e viverem melhor (A2).

A atividade elaborada pode ser uma forma de ensinar educação financeira, pois potencializa o aluno a ter conhecimento de situações reais (A5).

A situação-problema é bem realista, o que nos propicia mais estímulo para resolvê-la e aplicá-la no nosso dia-a-dia (A7).

Como futuro educador, precisamos ser criativos e associar bem com nosso cotidiano, a elaboração nos fez pensar muito de como podemos aplicar a atividade e compreender as dificuldades que podem surgir quando existe pensares distintos (A8).

D’ Ambrosio (2000) complementa que os alunos precisam ter conhecimento de matemática para enfrentar os problemas do cotidiano, saber analisá-los de forma crítica para que consigam fazer melhores escolhas. Dessa maneira, é de suma importância desenvolver momentos desafiadores, em que o aluno sinta-se motivado a envolver-se durante a atividade. Cabe ao professor relacionar os conteúdos desenvolvidos em sala de aula com o cotidiano, estimulando a autonomia, o pensamento crítico de seus alunos e a própria aprendizagem.

Por fim, diante da discussão dessa categoria, as principais manifestações de aprendizagem que surgiram do questionário metacognitivo, respondido pelos alunos, estão relacionadas: 1) ao desenvolvimento da autonomia, da criatividade, do pensamento crítico e reflexivo durante a resolução das tarefas investigativas e momentos de socialização; 2) à consciência metacognitiva; 3) à cooperação e troca de saberes do trabalho em grupo; 4) a cada tarefa investigativa de educação financeira estar vinculada ao cotidiano e a outras ciências, como por exemplo, a matemática e a economia, possibilitando estabelecer a ligação da teoria com a prática; 5) à oportunidade de o aluno se sentir professor ao produzir uma atividade de investigação matemática e trocar a tarefa entre os grupos; 6) à formulação, teste e validação de 
conjecturas; 7) ao raciocínio nas questões abertas de investigação matemática sobre educação financeira, em que vários fatores podem influenciar nos processos decisórios; 8) ao protagonismo, o aluno ser responsável pela sua própria aprendizagem e o professor atuar como mediador, instigar a investigação.

\section{b) Análise das dificuldades durante a resolução da tarefa}

Lusardi e Mitchell (2014) destacam que a maioria das pessoas em todo o mundo é considerada analfabeta financeiramente e confirmam a importância do conhecimento de economia no ensino de educação financeira, para que os alunos, ao aprenderem, possam fazer melhores escolhas financeiras. O licenciando A8 considera que a educação financeira envolve tanto o conhecimento de matemática como de economia para solucionar problemas financeiros do cotidiano:

Tivemos uma pequena dificuldade na interpretação da atividade, pois não percebemos alguns detalhes iniciais, era necessário ter conhecimento de economia, pois só por lógica e conhecimento de matemática resolvemos de forma errada (A8).

Em 1976, Flavel ampliou o conceito de metacognição, incluindo a autorregulação ${ }^{3}$, em função da necessidade de que o aluno recorra a sua estrutura cognitiva não apenas para identificar o que e quanto sabe, mas também para monitorar e supervisionar os seus próprios conhecimentos, como aprende, o que falta aprender, qual a melhor estratégia a ser utilizada para resolver determinado problema ou ampliar os seus conhecimentos em determinado assunto (ROSA, 2011). Portanto, a educação financeira engloba não somente o conhecimento de matemática financeira, mas também de economia, como ressalta o aluno A8, com o objetivo de que os alunos possam fazer melhores escolhas e analisar, de maneira mais aprofundada, problemas financeiros do cotidiano.

Chen e Volpe (1998) concluem que os alunos precisam melhorar seus conhecimentos de finanças pessoais e economia, pois sem conhecimento adequado

\footnotetext{
${ }^{3} \mathrm{~A}$ autorregulação é um sistema auto-organizado que necessita de cognição, emoção, motivação, objetivo e motivo para a ação. A construção da autorregulação depende do desenvolvimento de competências que permitem ao indivíduo saber o que necessita aprender, organizar, planejar e desenvolver, determinando objetivos e selecionando estratégias para a realização da atividade (BEBER; SILVA; BONFIGLIO, 2014).
} 
cometerão erros no mundo real, a incompetência limitará a capacidade de tomar decisões financeiras. A aluna A3 destaca o quanto foi difícil compreender a situação-problema, em função da quantidade de conceitos econômicos:

Sim, no início foi bem difícil começar a compreender o que tinha que ser feito, com muitos termos que nunca vi. Para mim foi a problematização mais complexa até agora (A3).

A aluna A3 também salienta que a partir de outra atividade desenvolveu o pensamento lógico e aprendeu sobre taxa de câmbio e desvalorização da moeda:

Aprendi muito com esta atividade, pois eu nem imaginava o que era câmbio quando falavam na televisão, parecia coisa de outro mundo, algo que era fora do meu entendimento. Agora entendi sobre desvalorização da moeda e ter um pensamento lógico (A3).

Portanto, a aluna A3 expõe que, inicialmente, não tinha conhecimento sobre taxa de câmbio e não compreendia o que era transmitido pela televisão, mas com a resolução da tarefa investigativa obteve êxito na aprendizagem e no desenvolvimento do pensamento lógico. Ao raciocinar (pensar) sobre o seu conhecimento sobre o assunto e adquirir consciência do quanto e como aprendeu, recorreu a suas estruturas metacognitivas. A metacognição, segundo Flavel (1979), é um pensar sobre o pensamento e o pensamento crítico deste sujeito também se relaciona com a metacognição.

Doly (1999) ressalta que a metacognição é útil para construir conhecimentos e competências com mais êxito, para aprender estratégias de resolução de problemas que favoreçam o sucesso e a autorregulação, para que os alunos se tornem mais autônomos na gestão das tarefas e nas aprendizagens, como se percebe, também, nos relatos das alunas A4 e A5:

Estipulamos diferentes tempos de permanência na cafeteria, e também o fato de comprarmos o lanche ou café. Estipulamos também o valor do café, pois o problema não informa esses detalhes o que dificulta a análise e requer muita atenção, por isso precisamos testar as conjecturas antes de validá-las (A4).

A questão está muito em aberto, podendo fazer muitas suposições, dificultando na escolha da cafeteria, pois a cada suposição a resposta pode ser mudada. Precisamos de um pensamento crítico dos custos (tempo, alimentação, entre outros) e benefícios que iremos ter a cada situação para fazer a melhor escolha. Poderia ter 
sido especificado o tempo de espera, se a pessoa faria ou não lanche assim como o valor gasto na cafeteria $C$ para facilitar, são tantas possibilidades que dificulta a análise (A5).

Para Flavell (1987) o conhecimento metacognitivo e as experiências metacognitivas estão interligados, na medida em que o conhecimento permite interpretar as experiências e agir sobre elas, contribuindo para o desenvolvimento e a modificação desse conhecimento. Nesse sentido, investir na promoção de estratégias de autorregulação da aprendizagem valoriza e estimula o desenvolvimento de habilidades e competências que promovem o aprender e o reaprender. O aluno A2 destaca que o grupo apresentou dificuldade em compreender a atividade e encontrar as equações, que estão acostumados a utilizar formulário:

Tivemos uma dúvida na questão que tinha de passar de dólar para rublos, mas conseguimos concluir, ainda tivemos dúvidas enquanto a generalização de algumas fórmulas, na verdade não estamos acostumados a encontrar fórmulas, sempre usamos formulário (A2).

Em outra atividade, o aluno A1 manifesta dificuldade em trabalhar com questões investigativas de caráter aberto, expõe que escolher é uma tarefa difícil, que existem vários fatores que fazem parte do processo de decisão, o que torna a análise mais complexa, pois é necessário pensar em várias hipóteses:

Nas investigações precisamos levar várias situações em consideração, o que torna a atividade mais complexa. Isso faz estimularmos nosso cérebro a entender que existem uma série de fatores a se considerar e que escolhermos um modelo que beneficie o indivíduo não é algo simples. Tomar uma decisão parece simples, rápido e prático, mas escolher é uma tarefa difícil e complicada, porque devemos incluir várias hipóteses para a análise. Isso é positivo, pois faz compreendermos que as coisas não são tão superficiais quanto parecem (A1).

Assim sendo, quando a metacognição está presente, o aprendiz reconhece suas potencialidades e/ ou dificuldades, ultrapassando limites e obstáculos. O avanço, conforme Beber, Silva e Bonfliglio (2014) está na tomada de consciência do saber e do não saber, em um processo constante de autoavaliação para alcançar a autorregulação.

Andretta et al. (2010) ressaltam que o indivíduo experimenta diversas estratégias de aprendizagem desde criança, tendendo sempre a repetir aquela com a 
qual obteve maior eficácia. Dessa maneira, cada um tem uma estratégia que funciona melhor para si; o processo metacognitivo é diferente para cada um. Ainda segundo os autores, quanto melhor a capacidade metacognitiva, melhores as habilidades de aprendizagem, sendo possível otimizar o tempo e a qualidade do estudo. A estreita relação da metacognição com a aprendizagem deve ser explorada, visto que desempenha um importante papel na otimização e qualificação do estudo e de resolução de problemas.

O aluno A1 relata que o grupo não estava visualizando a lógica de converter moeda nacional em estrangeira e que não conseguiram encontrar uma generalização, para uma pergunta, que pudesse ser utilizada para qualquer situação da mesma natureza:

Tivemos dificuldade para interpretar a pergunta da letra "c", pois não estávamos enxergando a lógica de usar a moeda real para multiplicar o valor total do dólar/euro que precisaria para comprar a moeda rublos. E outra situação, é não conseguirmos achar uma formalização para a pergunta da letra " $d$ ". Claro que depois, compreendemos essas dificuldades a partir de um exemplo mais simples elaborado por nós (A1).

Ponte, Brocardo e Oliveira (2015) comentam que investigar não significa trabalhar com problemas muito difíceis, mas trabalhar com situações que no início se apresentam de modo confuso, como manifesta o aluno A1, e que se procura clarificar; é justamente em função da sua estrutura aberta que as tarefas investigativas apresentam elevado grau de dificuldade. O aluno A8, também, destaca que no início não sabia o que era taxa de câmbio e a tarefa investigativa foi importante para a compreensão do conceito, desenvolvimento do pensamento crítico e estabelecimento da relação entre teoria e a prática:

Algumas informações como, por exemplo, taxa de câmbio, nunca ouvimos falar e nesse caso foi a turma inteira. O interessante é que a partir da atividade de investigação matemática, todos conseguiram definir o que era, através do pensamento crítico, formalizando os cálculos e ligando a teoria com a prática (A8).

Segundo Rosa (2011) a resolução de problemas é considerada uma atividade que impulsiona o pensamento e ocupa papel central no processo de ensinagem. Esta ideia também pode ser estendida a tarefas de investigação matemática, que são 
situações-problemas abertas, em que se impulsiona o pensamento na busca de estratégias para solucionar o problema, além de avaliá-las para detectar possíveis erros que tenham sido cometidos. Portanto, os processos metacognitivos na investigação matemática também cumprem uma função autorreguladora. Ponte, Brocardo e Oliveira (2015, p. 22) destacam que “as investigações matemáticas constituem uma das atividades que os alunos podem realizar e que se relacionam, de muito perto, com a resolução de problemas". A diferença, de acordo com os autores, é que em uma tarefa investigativa não existe um método que permita a resolução imediata, enquanto um problema pode ser resolvido a partir de um método conhecido.

Diante da discussão realizada nessa categoria, pode-se perceber que as principais dificuldades encontradas pelos alunos nas tarefas investigativas de educação financeira estão relacionadas à falta de conhecimento de economia; insegurança na formulação de conjecturas/generalizações em função da dependência da utilização de formulários (fórmulas); ausência de prática na resolução de problemas de caráter aberto.

\section{Considerações finais}

Este estudo, de abordagem qualitativa, teve o propósito de investigar a aprendizagem e principais dificuldades dos licenciandos em matemática, de uma universidade no estado do Rio Grande do Sul, com relação a tarefas investigativas de educação financeira, a partir de questionário metacognitivo. Com a análise dos dados foi possível atingir o objetivo proposto. Os dados foram agrupados em duas categorias: a) Manifestações de aprendizagem e b) Análise das dificuldades durante a resolução da tarefa. Os dados representativos dessas categorias demonstram que existiu aprendizado, de acordo com as respostas dos licenciandos, por meio da resolução das tarefas de investigação matemática, reflexões nos pequenos grupos, discussões no momento de socialização das atividades em sala de aula e análise das dificuldades durante a execução das tarefas.

Ao relacionar as tarefas investigativas à metacognição pode-se dizer que as atividades estimularam os alunos a identificar o que sabem em relação ao tema de cada situação-problema e quais são as melhores estratégias a serem utilizadas para se chegar a alguma conclusão, desenvolvendo a autonomia e o senso crítico. De acordo com o 
relato dos alunos, pode-se perceber que as tarefas de investigação matemática propostas (situações-problemas abertas) impulsionaram o pensamento na busca de estratégias para solucionar o problema, além de avaliá-las para detectar possíveis erros que tenham sido cometidos, ficando evidente a consciência metacognitiva dos alunos com relação ao grau de dificuldade apresentado em cada tarefa e quais seriam as causas.

Os pequenos grupos percorreram caminhos diferentes e fizerem descobertas importantes durante a resolução de cada problema; quando compararam os resultados, no momento da socialização para o grande grupo, perceberam que poderiam ter escolhido outros trajetos ou que não observaram algum fator importante que fazia parte da análise e influenciava no processo de tomada de decisão. Os alunos demonstraram entusiasmo ao encontrar generalizações pela primeira vez (sempre as fórmulas eram dadas prontas em aulas anteriores), testar e validar as conjecturas e perceber que não necessariamente a resposta encontrada é a única que está correta.

Diante desse contexto, é inegável o potencial da investigação matemática na aprendizagem, no desenvolvimento da consciência metacognitiva e no pensamento crítico dos alunos. Nesse sentido, foi escolhida a metodologia da investigação matemática para ensinar educação financeira, com o objetivo de favorecer o aprendizado, ligar a teoria com a prática (situações-problema do cotidiano), desenvolver o pensamento crítico e as habilidades dos futuros professores da educação básica e/ou ensino superior.

\section{Referências}

ABRANTES, P. Investigações em geometria na sala de aula. In: ABRANTES, P. et al. Investigações matemáticas na aula e no currículo. Lisboa: APM e Projecto MPT, 1999. Disponível em: http://www.rc.unesp.br/igce/demac/maltempi/cursos/curso3/Artigos/Artigos_arquivos /p_153-167.pdf. Acesso em: 24 ago. 2019.

ANDRETTA, I. et al. Metacognição e Aprendizagem: como se relacionam? Revista PSICO, Porto Alegre, 2010.

BEBER, B.; SILVA, E.; BONFIGLIO, S. Metacognição como processo da aprendizagem. Revista Psicopedagogia, São Paulo, 2014.

BRASIL. Parâmetros curriculares nacionais: matemática. Secretaria de Educação Fundamental. Brasília, 1998. 
BRASIL. Ministério da Educação. BNCC: Base Nacional Comum Curricular. Brasília: Ministério da Educação, 2017. Disponível em: http://basenacionalcomum.mec.gov.br/documentos/bncc2versao.revista.pdf. Acesso em: 16 ago. 2019.

CHEN, H.; VOLPE, R. P. An analysis of personal financial literacy among college students. Financial Services Review, v. 7, n. 2, p. 107-128, 1998.

D’AMBrosio, U. Educação Matemática: da teoria à prática. São Paulo: Papirus, 2000.

DOLY, A. M. Metacognição e mediação na escola. In: GRANGEAT, M. (Coord.). $A$ metacognição, um apoio ao trabalho dos alunos. Trad. Teresa Maria Estrela. Porto, Portugal: Porto Editora, 1999. p. 17-59.

FLAVELL, J. H. Metacognition and cognitive monitoring: a new area of cognitive developmental inquiry. American Psychologist, v. 34, n. 10, p. 906-911, 1979.

FLAVELL, J. H. Speculation about the nature and development of metacognition. In: WERNERT, F. E.; KLUWE, R. H. (Eds.). Metacognition, Motivation and Understanding. Hillsdale, NJ: Lawrence Erlbaum Associates, 1987.

FRANZONI, P.; DEL PINO, J. C.; OLIVEIRA, E. C. Contribuições da economia para a alfabetização científica: uma proposta para a educação básica. Revista Contexto e Educação, ano 33, n. 105, p. 119-141, mai./ago. 2018.

FRANZONI, P.; MARTINS, S. N.; QUARTIERI, M. T. A educação financeira como política pública no ensino básico: algumas reflexões. Revista Educação, Cultura e Sociedade, v. 8, n. 2, p. 383-395, jul./dez. 2018.

GOLDENBERG, E. P. Quatro funções da investigação na aula de matemática. In: ABRANTES, P. et al. Investigações matemáticas na aula e no currículo. Lisboa: APM e Projecto MPT, 1999.

GERHARDT, T. E.; SILVEIRA, D. T. Métodos de pesquisa. Porto Alegre: EdUFRGS, 2009.

GONTIJO, C. H. Resolução e formulação de problemas: caminhos para o desenvolvimento da criatividade em matemática. In: SIPEMAT: Pesquisa em educação matemática: um olhar ampliado sobre a sala de aula, 2006, Recife. Anais... Recife: UFPE, 2006.

GRILLO, M.; FREITAS, A. L. Autoavaliação: Por que e como realizá-la. In: GRILLO, M.; GESSINGER, R. Por que falar ainda em avaliação? Porto Alegre: EDIPUCRS, 2010.

KISTEMANN JR., M. A. Sobre a produção de significados e a tomada de decisão de indivíduosconsumidores. Tese (Doutorado em Educação Matemática) — Universidade Estadual Paulista "Júlio de Mesquita Filho", São Paulo, 2011.

LUSARDI, A.; MITCHELL, O. S. The Economic Importance of Financial Literacy: Theory and Evidence. Journal of Economic Literature, v. 52, n. 1, p. 5-44, 2014.

MANKIW, N. G. Introdução à Economia. São Paulo: Pioneira Thompson Learning, 2005.

MASETTO, M. T. Competência pedagógica do professor universitário. São Paulo: Summus, 2003.

MORAES, R.; GALIAZZI, M. do C. Análise textual discursiva. Ijuí: Editora UNIJUÍ, 2016. 
MOREIRA, S. et al. Ensino da matemática financeira para alunos do $8^{\circ}$ e $9^{\circ}$ ano do ensino fundamental: uma proposta na perspectiva da educação matemática crítica. Revista Espacios, v. 38, n. 30, p. 1-10, 2017.

PEIXOTO, M. A. P.; BRANDÃO, M. A. G.; SANTOS, G. Metacognição e tecnologia educacional simbólica. Revista Brasileira de Educação Médica, v. 31, n. 1, p. 67-80, 2007.

PONTE, J. P. da; BROCARDO, J.; OLIVEIRA, H. Investigações matemáticas na sala de aula. Belo Horizonte: Autêntica, 2015.

ROSA, C. T. W. da. A metacognição e as atividades experimentais no ensino de Física. 346p. Tese (Doutorado em Educação Científica e Tecnológica) - Universidade Federal de Santa Catarina, Florianópolis, 2011.

SANDRONI, P. Dicionário de Economia do Século XXI. 4. ed. Rio de Janeiro: Record, 2008.

SANTOS, W. L. P. dos. Educação científica na perspectiva de letramento como prática social: funções, princípios e desafios. Revista Brasileira de Educação, v. 12, n. 36, set./dez. 2007.

SKOVSMOSE, O. Desafios da Educação Matemática Crítica. São Paulo: Papirus, 2000.

TEIXEIRA, J. Um estudo diagnóstico sobre a percepção da relação entre educação financeira e matemática financeira. Tese (Doutorado em Educação Matemática) - Pontifícia Universidade Católica de São Paulo, São Paulo, 2015. 